\title{
Qualitative/Chemical Analyses of Ankaferd Hemostat and Its Antioxidant Content in Synthetic Gastric Fluids
}

\author{
Ahmet Koluman, ${ }^{1}$ Nejat Akar, ${ }^{2}$ Umit Y. Malkan, ${ }^{3}$ and Ibrahim C. Haznedaroglu ${ }^{3}$ \\ ${ }^{1}$ National Food Reference Laboratory, Department of Mineral Analyses, Ministry of Food Agriculture and Livestock, \\ 06170 Ankara, Turkey \\ ${ }^{2}$ Department of Pediatric Hematology, TOBB-ETU Hospital, 06570 Ankara, Turkey \\ ${ }^{3}$ Department of Adult Hematology, Hacettepe University Medical School, 06100 Ankara, Turkey
}

Correspondence should be addressed to Umit Y. Malkan; umitmalkan@hotmail.com

Received 30 November 2015; Revised 29 December 2015; Accepted 6 January 2016

Academic Editor: Gail B. Mahady

Copyright (C) 2016 Ahmet Koluman et al. This is an open access article distributed under the Creative Commons Attribution License, which permits unrestricted use, distribution, and reproduction in any medium, provided the original work is properly cited.

\begin{abstract}
Introduction. Ankaferd hemostat (ABS) is the first topical haemostatic agent involving the red blood cell-fibrinogen interactions. The antihemorrhagic efficacy of ABS has been tested in controlled clinical trials. The drug induces the formation of an encapsulated complex protein web with vital erythroid aggregation. The aim of this study is to detect the essential toxicity profile and the antioxidant molecules inside ABS. Methods. The pesticides were analyzed by GC-MS and LC-MS. The determination by ICP-MS after pressure digestion was performed for the heavy metals. HPLC was used for the detection of mycotoxins. Dioxin Response Chemically Activated Luciferase Gene Expression method was used for the dioxin evaluation. TOF-MS and spectra data were evaluated to detect the antioxidants and other molecules. Results. TOF-MS spectra revealed the presence of several antioxidant molecules (including tocotrienols, vitamin E, tryptophan, estriol, galangin, apigenin, oenin, 3,4-divanillyltetrahydrofuran, TBHQ, thymol, BHA, BHT, lycopene, glycyrrhetinic acid, and tomatine), which may have clinical implications in the pharmacobiological actions of ABS. Conclusion. The safety of ABS regarding the presence of heavy metals, pesticides, mycotoxins, GMO and dioxins, and PCBs was demonstrated. Thus the present toxicological results indicated the safety of ABS. The antioxidant content of ABS should be investigated in future studies.
\end{abstract}

\section{Introduction}

Ankaferd hemostat, $\mathrm{ABS}$, is the first topical haemostatic agent involving the red blood cell- (RBC-) fibrinogen interactions. ABS comprises a standardized mixture of the plants Thymus vulgaris, Glycyrrhiza glabra, Vitis vinifera, Alpinia officinarum, and Urtica dioica (reviewed in [1]). The overall hemostatic effects of ABS depend upon the protein agglutination and polymerization modulating the erythroid aggregation within the vascular endothelial system $[1,2]$. Prohemostatic and antithrombin activities of Ankaferd hemostat are linked to the fibrinogen gamma chain and prothrombin [2]. ABS induces the formation of an encapsulated complex protein web with vital erythroid aggregation covering the entire physiological hemostatic process [3]. The unique hemostatic properties of ABS provide a balanced hemostasis representing a basis for physiological wound healing [4-8]. The structural and functional properties of the proteins related to the biological effects of ABS have previously been investigated with the functional proteomics [9] and transcriptomics [10] analyses.

Randomized clinical trials (RCT) indicated the safety and efficacy of ABS for the topical control of clinical hemorrhages in a wide variety of settings [11-18]. Likewise, the cumulating preliminary data points out the expanding spectrum of ABS. For instance, a recent clinical study by Patiroglu et al. has demonstrated that oral topical ABS use at the beginning of chemotherapy could provide less oral mucositis when compared to the control group in the pediatric patients with cancer [19]. Moreover, experimental antineoplastic activities of ABS have been shown in rats and cancer cell lines [20-22].

ABS may be used as a supportive agent together with the antituberculosis treatments during debridement of multiple 
drug-resistant $M$. tuberculosis caused osteomyelitis and lymphadenitis lesions [23]. Oral/endoscopic ABS administration has already been performed in the gastrointestinal system (GIS) hemorrhages [24-27]. Moreover, ABS is active against multiresistant bacteria, such as methicillin-resistant Staphylococcus aureus (MRSA), Enterococcus spp., generic Escherichia coli, Klebsiella spp., Acinetobacter spp., and Pseudomonas spp., as well as fungi such as Aspergillus spp., Mucor spp., and Candida albicans [28-31]. Therefore, anti-infective properties of the ABS may be considered for the supportive usage of this agent in numerous infectious disorders in the future.

Expanding clinical spectrum of ABS is evident. Thus, additional toxicological data for the possible topical and/or systemic usage of this unique haemostatic agent are needed. The aim of this study is to detect essential toxicity profile (heavy metals, pesticides, mycotoxins, GMO (genetically modified organisms), dioxins, and polychlorinated biphenyls (PCBs) analyses). Furthermore, the antioxidant molecules inside ABS are also searched. The antioxidant system might be related to the ABS-induced pleiotropic actions (hemostasis, infection, cellular proliferation, and vessel wall dynamics) $[1,32,33]$. Likewise, ABS attenuated the oxidative and inflammatory changes caused by ASA-induced gastric mucosal damage in a previous study [32]. Thus, we also aimed to investigate the fate of antioxidant content of ABS when exposed to the synthetic gastric fluid.

\section{Materials and Methods}

Ten milliliters (mL) of ABS sample was transferred to the laboratory (Lab) under cold chain in a residue-free sterile tube. The sample was taken into analyses within 30 minutes after the handling of ABS in the Lab.

For the analyses of heavy metals, the organic molecules in $0.3 \mathrm{~mL}$ of $\mathrm{ABS}$ were digested using $\mathrm{NHO}_{3}$ and $\mathrm{H}_{2} \mathrm{O}_{2}$ under pressured microwave oven and samples were read in ICP-MS according to the method referred by the Nordic Committee on Food Analysis (NMKL) 186 (NMKL trace elements-As, $\mathrm{Cd}, \mathrm{Hg}, \mathrm{Pb}$, and other elements. The specification by ICP-MS after pressure digestion was conducted (NMKL 186) (2007)).

For the pesticides analyses, $1 \mathrm{~mL}$ of ABS sample was taken for extraction of pesticides. After the extraction, pesticides were analyzed in Gas Chromatography Mass Spectroscopy (GC-MS) and Liquid Chromatography Mass Spectroscopy (LC-MS) using the methods related with the analytes (EPA 1668.821-R-00-002, December 1999).

For the mycotoxins detection, $1 \mathrm{~mL}$ of ABS sample was used for the extraction and the extracts were injected to High Performance Liquid Chromatography (HPLC) using the method of AOAC (AOAC Official Method 999.07).

For the GMO (genetically modified organisms) analyses, $1 \mathrm{~mL}$ of ABS sample was used to extract DNA with Qiagen DNeasy Blood \& Tissue Kit and QIAprep Spin Miniprep Kit. After extraction gel electrophoresis was held using the method International Standardization Organization, ISO 24276 (ISO 24276: Foodstuffs-Methods of analysis for the detection of genetically modified organisms and derived products, 2009) and ISO 21569 (ISO21569: FoodstuffsMethods of Analysis for the Detection of Genetically Modified Organisms and Derived Products-Qualitative Nucleic Acid Based Methods, 2005).

Regarding the dioxin analyses, $3 \mathrm{~mL}$ of ABS sample was used for extraction and Dioxin Response Chemically Activated Luciferase Gene Expression (DR Calux) method was used for the dioxin evaluation.

For the PCB analyses, EPA 1668 and CEN 1528 methods have been utilized for the evaluation.

In order to detect the antioxidants and other molecules, $1 \mathrm{~mL}$ of ABS sample was diluted and given to Time of Flight Mass Spectroscopy and spectra were evaluated using the online library. The antioxidant molecules were evaluated using the method determined by AOAC 983.15, 2007.

For the detection of fate of ABS in synthetic gastric fluid $(S G F)$, synthetic gastric fluid was prepared as previously described by Molly et al. [34]. SGF exposure tests were carried out after the inoculation of ABS on the minutes of $1,5,10$, and 15. Triplicate samples of $2 \mathrm{~mL}$ of ABS were mixed with $10 \mathrm{~mL}$ of SGF ( $\mathrm{pH}$ adjusted to 1.0 with $\mathrm{HCl}$ ) and each was used in the tests. The buffering effect of the ABS was controlled; the $\mathrm{pH}$ value of the mix was adjusted to 1.0 as needed.

Apigenin detection was held according to the method published by Xiao et al. [35]. Glass-stoppered test tubes $\left(15 \mathrm{~cm}^{3}\right)$ with a Teflon-coated magnetic stirrer were used to make saturated solutions (about $8.0 \mathrm{~cm}^{3}$ ) of apigenin or apigenin 7-O-rhamnosylglucoside with excess solid solute (about $0.3 \mathrm{~g}$ ) in these solvents. The test tubes were closed up with paraffin to avoid evaporation of solvents. After that, the test tubes were put straight in a constant-temperature thermostatic bath (PolyScience Circulators 9501, USA) with a temperature accuracy of $\pm 0.05 \mathrm{~K}$ and stability of $0.01 \mathrm{~K}$. Undissolved solid and solution were permitted to settle about 24 to $36 \mathrm{~h}$ to ensure equilibrium before sampling. For each test tube, three samples of approximately 0.2 to $0.3 \mathrm{~cm}^{3}$ were withdrawn from the clear saturated solution using preheated glass syringes.

The glass syringe with saturated solution was measured by a Sartorius CP225D analytical balance with an accuracy $\pm 0.01 \mathrm{mg}$. In order to prevent evaporation of solvents during the weighing process, the needle was locked with silicone rubber. The saturated solution was added to the volumetric flask $\left(10 \mathrm{~cm}^{3}\right)$ immediately to avoid precipitating. Afterward, the mass of glass syringes with the remaining solution was measured. The mass of saturated solutions that were placed into volumetric flasks can be found. The solutions of samples used to examine were diluted to mark with methanol. The reference standard solution containing $16 \mu \mathrm{g} \cdot \mathrm{cm}^{-3}$ of apigenin and $15 \mu \mathrm{g} \cdot \mathrm{cm}^{-3}$ of apigenin 7-O-rhamnosylglucoside was set in methanol, respectively. To determine the concentration of apigenin and apigenin 7-O-rhamnosylglucoside, an HPLC system (LC-10AD, Shimadzu, Japan) was used. All chromatographic studies were done on Diamonsil ODS C18 column $(250 \mathrm{~mm} \times 4.6 \mathrm{~nm}, 5 \mu \mathrm{m})$ with the wavelength of detector set at 256 and $333 \mathrm{~nm}$, respectively. The mobile phase was composed of acetonitrile and an aqueous solution having a volume fraction of $0.1 \%$ of phosphoric acid in a volume ratio 
TABLE 1: The searched specific pesticides (which are not present in ABS) that are analyzed by Gas Chromatography Mass Spectroscopy (GCMS) and Liquid Chromatography Mass Spectroscopy (LC-MS) methods.

\begin{tabular}{|c|c|}
\hline GC-MS & $\begin{array}{l}\text { 2-Phenylphenol, Acetochlor, Acrinathrin, Alachlor, Aldrin, Dieldrin, Benfluralin, Bifenox, Bifenthrin, Biphenyl, } \\
\text { Bromophos ethyl, Bromophos methyl, Bromopropylate, Captan, Chlordane, Chlorfluazuron, Chlormephos, } \\
\text { Chlorothalonil, Chlorpyrifos, Chlorpyrifos-methyl, Cyfluthrin, Cypermethrin, DDT, Deltamethrin, Dichlobenil, } \\
\text { Dicloran, Dicofol, Diphenylamine, Endosulfan, Endrin, Fenarimol, Fenchlorphos, Fenitrothion, Fenpropathrin, } \\
\text { Fenvalerate, Esfenvalerate, Flucythrinate, Folpet, Fonofos, Formothion, Heptachlor, Hexachlorobenzene, } \\
\text { Hexachlorocyclohexane, Indoxacarb, Iprodione, Kresoxim-methyl, Lambda-cyhalothrin, Lindane, Lufenuron, } \\
\text { Methoxychlor, Metribuzin, Nitralin, Nitrofen, Nuarimol, Oxyfluorfen, Parathion, Parathion-methyl, Permethrin, } \\
\text { Procymidone, Propargite, Prothiofos, Quinomethionat, Quintozene, Spirodiclofen, Tau-fluvalinate, Tecnazene, } \\
\text { Tetradifon, Tetrasul, Tolclofos-methyl, Triallate, Trichloronat, Trifloxystrobin, Trifluralin, and Vinclozolin }\end{array}$ \\
\hline LC/MS/MS & 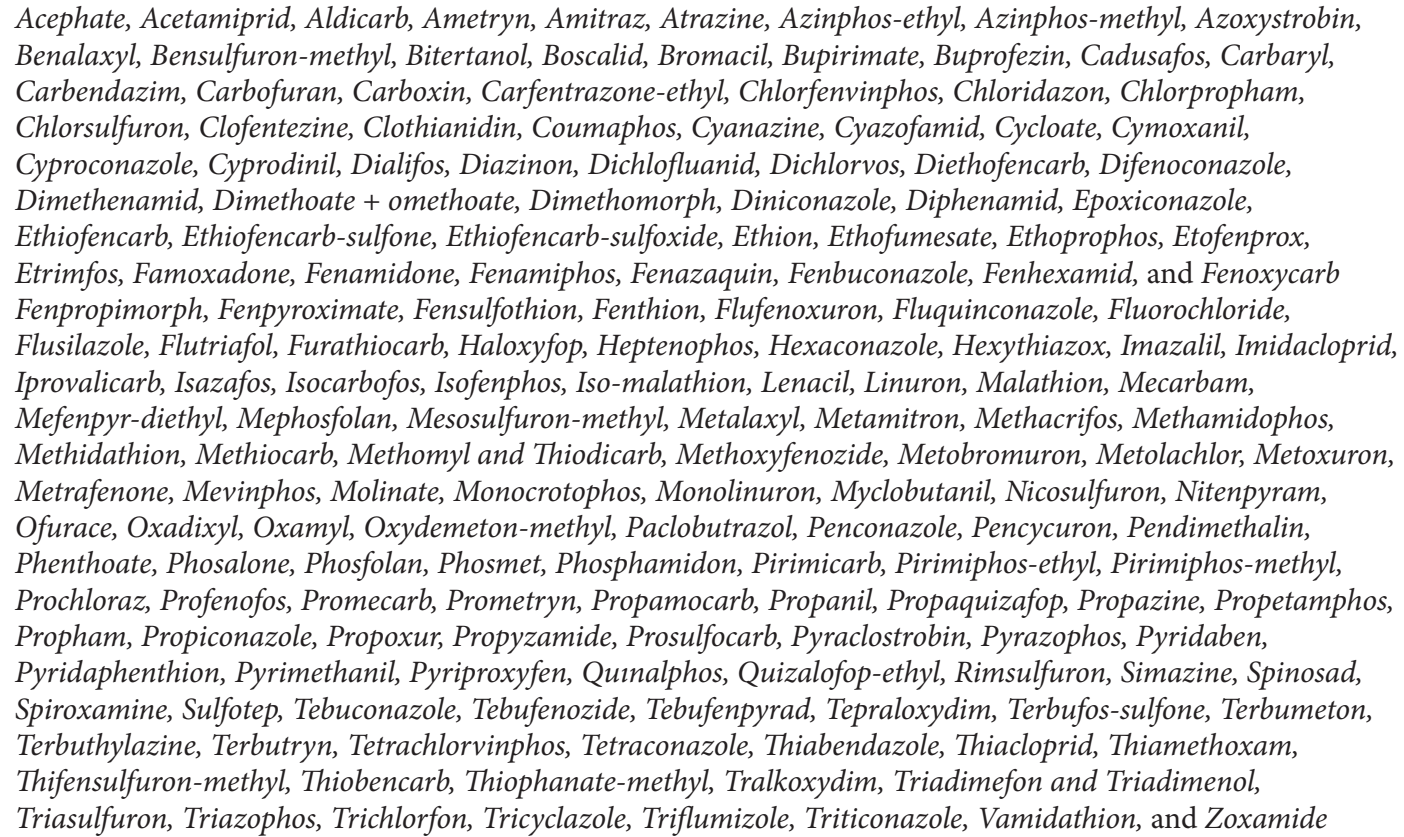 \\
\hline
\end{tabular}

of $35: 65$ and $25: 75$ at a flow rate of $1.0 \mathrm{~cm}^{3} \cdot \mathrm{min}^{-1}$. The injected volumes of sample and reference standard solutions were $0.020 \mathrm{~cm}^{3}$. All chromatograph procedures were done at room temperature.

Tocopherol and tocotrienol detection was done according to the method described by Albahrania and coworkers [36]. All samples were organized as follows: $100 \mu \mathrm{L}$ of sample and $100 \mu \mathrm{L}$ of Milli-Q water were added to a borosilicate glass tube and vortexed. Next, $200 \mu \mathrm{L}$ of methanol having the deuterated internal standard was injected to this combination, vortexed, and then equilibrated for $10 \mathrm{~min}$ at room temperature. Analytes were extracted with addition of $1 \mathrm{~mL}$ of HPLC grade hexane to the combination and then vortexed extensively before centrifugation at $3000 \mathrm{rpm}$ for $5 \mathrm{~min}$ at room temperature. The organic layer was moved to a new glass tube and dried below a stream of nitrogen gas at room temperature and then reconstituted in $250 \mu \mathrm{L}$ methanol. This sample preparation process was performed under depressed light. The reconstituted sample $(1 \mu \mathrm{L})$ was added to the Agilent LC-MSMS system (Agilent 1290 Infinity LC and Agilent 6490 Triple Quadrupole Mass Spectrometer, Agilent Technologies, Victoria, Australia). Chromatographic isolation of analytes was conducted with a Pursuit ${ }^{\circledR}$ XRs C18 column $(20 \mathrm{~mm} \times 2 \mathrm{~mm} \times 3 \mu \mathrm{m})$ and MetaGuard $2.0 \mathrm{~mm}$
Pursuit XRs $3 \mu \mathrm{m} \mathrm{C18}$ from (Agilent Technologies). The mobile phases consisted of mobile phase A (MP-A), $0.1 \%$ formic acid in Milli-Q water containing 2\% methanol and mobile phase B (MP-B), $0.1 \%$ formic acid in methanol. A constant flow rate of $0.2 \mathrm{~mL} / \mathrm{min}$ and a gradient profile from $80 \%$ to $100 \%$ of MP-B were employed.

\section{Results}

The quantitative analyses of the heavy metals $(\mathrm{Pb}, \mathrm{Cd}, \mathrm{Hg}$, $A s$, and Bor) in the ABS sample revealed that ABS does not contain $\mathrm{Pb}, \mathrm{Cd}, \mathrm{Hg}$, and As (the concentrations of the heavy metals were $\mathrm{Pb}$ : 0,008 ppb; Cd: 0,000 ppb; Hg: 0,004 ppb; As: 0,000 ppb, and Bor: 0,000 ppb, resp.).

The chromatographic analyses of the pesticides analyses in the ABS sample revealed that ABS does not contain pesticides. The searched specific pesticides (which are not present in ABS) that were analyzed by GC-MS and LC-MS methods were depicted in Table 1.

The analyses focusing on mycotoxins detection in the ABS sample via using the HPLC method revealed that ABS does not contain mycotoxins (namely, Aflatoxin B1, Aflatoxin B2, Aflatoxin G1, and Aflatoxin G2; total aflatoxins were not present in $\mathrm{ABS}$ ). 


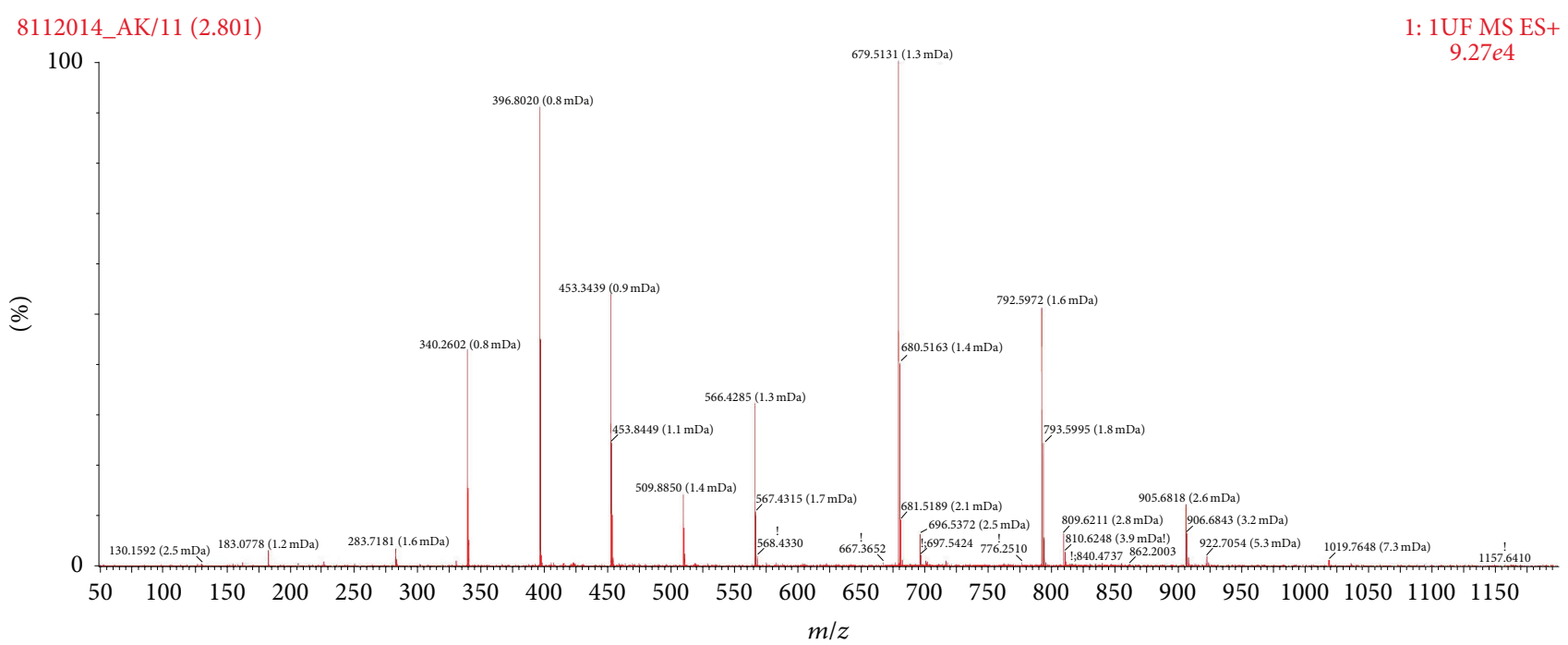

FIGURE 1: Antioxidant content of Ankaferd hemostat (ABS) detected by Time of Flight Mass Spectroscopy (TOF-MS). The complicating background noise due to the complex molecular library of ABS prevented the exact specifications of the molecules evaluated from the TOFMS. Nevertheless, careful analyses on TOF-MS spectra exactly revealed the presence of some antioxidants such as tocotrienols, members of the vitamin E family, tryptophan, estriol, galangin, apigenin, oenin, 3,4-divanillyltetrahydrofuran, tertiary butylhydroquinone (TBHQ), thymol, BHA (butylated hydroxyanisole), BHT (butylated hydroxytoluene), lycopene, enoxolone/glycyrrhetinic acid or glycyrrhetic acid, and tomatine.

The GMO analyses regarding the detection of genetically modified organisms in the ABS sample indicated that any plasmid extraction had not been realized, indicating that ABS does not have a GMO process during the preparation process.

The dioxin analyses in the $A B S$ sample revealed that $\mathrm{ABS}$ does not contain toxic dioxin and dioxin-like chemical compounds.

The complicating background noise due to the complex molecular library of ABS prevented the exact quantitative specifications evaluated from the Time of Flight Mass Spectroscopy (TOF-MS) and spectra, regarding the presence of the antioxidants and other specific molecules in the ABS sample. Nevertheless, careful analyses on TOF-MS spectra exactly revealed the presence of some antioxidants (such as tocotrienols, members of the vitamin E family, tryptophan, estriol, galangin, apigenin, oenin, 3,4-divanillyltetrahydrofuran, tertiary butylhydroquinone (TBHQ), thymol, BHA (butylated hydroxyanisole), BHT (butylated hydroxytoluene), lycopene, enoxolone/glycyrrhetinic acid or glycyrrhetic acid, and tomatine) (Figure 1). The concentrations of the antioxidants and other specific molecules in the ABS sample have not been affected after the exposure to the synthetic gastric fluid.

\section{Discussion}

In this study, the safety profile for ABS focusing on the presence of heavy metals, pesticides, mycotoxins, GMO (genetically modified organisms), and dioxin has been demonstrated. ABS is composed of standardized plant extracts including Alpinia officinarum, Glycyrrhiza glabra, Thymus vulgaris, Urtica dioica, and Vitis vinifera. ABS-induced pharmacological modulation of essential erythroid proteins (ankyrin, spectrin, and actin) can cause vital erythroid aggregation via acting on fibrinogen gamma. ABS also has pleiotropic effects particularly in the tissue healing and has anti-infective properties $[1,3,9,10,33,37,38]$. The toxicological results of the present study have provided the basis for the future ABS clinical trials in the fields of clinical hemostasis, wound healing, burn treatment, and anti-infective and antineoplastic approaches [4, 22, 39-47]. Moreover, next-generation RBC-related hemostatics, such as $\mathrm{ABS}$ nanohemostat, have already been designated in the essential treatment of life-threatening bleedings by restoring physiological hemostasis via acting on RBCs $[48,49]$. The safety profile for ABS obtained from this present report opens new avenues for the nanomedicinal production of novel chimeric plant-based hemostatic agents as of ABS nanohemostat $[48,49]$. Although our toxicological study should be accepted as a clue for the safety of the plant-based topical hemostatics, the issue is far from being completely resolved. For the active substances of plant extracts, exact safe levels of potential human exposure cannot be determined due to the GRAS (generally regarded as safe) ingredients (FDA, GRAS List of Some Chemicals and Plants (http://www.accessdata.fda.gov/scripts/cdrh/cfdocs/cfcfr/CFRSearch.cfm?fr= 182.20)).

In our present study, TOF-MS spectra revealed the presence of several antioxidant molecules (including tocotrienols, members of the vitamin E family, tryptophan, estriol, galangin, apigenin, oenin, 3,4-divanillyltetrahydrofuran, tertiary butylhydroquinone (TBHQ), thymol, BHA (butylated hydroxyanisole), BHT (butylated hydroxytoluene), lycopene, enoxolone/glycyrrhetinic acid or glycyrrhetic acid, and tomatine), which may have clinical implications in the pharmacobiological actions of ABS hemostatic agent. Furthermore, the concentrations of the antioxidants and other specific 
molecules in the ABS have not been affected after the exposure to the synthetic gastric fluid. Those findings have provided the basis for the future ABS clinical trials that will be designed for the oral systemic administration to control hemorrhages of the GIS tract. The contact of the gastric mucosa with the destructive factors could produce pathological changes such as ongoing inflammatory process, hemorrhagic erosions, and even acute ulcers. Hasgul and coworkers investigated the contribution of reactive oxygen species (ROS) in acute gastric mucosal injury by acetylsalicylic acid (ASA) and the effects of ABS in a rat model [32]. They demonstrated the biological effects of ROS as assessed by determining the tissue and plasma levels of malondialdehyde, the products of lipid peroxidation, as well as the activity of superoxide dismutase and the scavenger of reactive oxygen species produced by ASA in the experiment group. Furthermore, MPO activity as well as the NO and tumor necrosis factor (TNF) levels also demonstrated important improvement by ABS therapy. In their study, ABS attenuated the oxidative and inflammatory changes caused by ASA-induced gastric mucosal injury in rats [32]. Our present findings about the antioxidants of ABS content that had not been negatively affected after the exposure to the acidic gastric fluid further enlightened those previous experiments. The topical effects of ABS on GI system such as esophagus, stomach, intestines, liver, spleen, and vessels have been extensively searched in previous animal models [32, 40, 41, 50-58]. All of those data represent the basis for future clinical trials regarding the efficacy and safety of ABS in a wide variety of GI disorders such as infection, inflammation, and cancer.

Experimental trials indicated that $\mathrm{ABS}$ is effective in wound healing. Aktaş et al. have demonstrated that application of ABS after the tooth extraction can cause increased secretion of collagen type 1 , collagen type 3 , smooth muscle actin, fibronectin, beta 2 microglobulin, vascular endothelial growth factor, and cyclooxygenase-2, which are very effective in early phases of wound healing. ABS had provided rapid wound healing with the actions of those molecules [42]. Moreover, ABS can cause leukocyte infiltrations, vascularization, and fibroblast proliferation in the mucosal tissue that could facilitate the wound healing process [4]. Kaya and coworkers topically used ABS on the burning tissue and provided decrements in the wound diameter and inflammation, accelerated tissue fibrosis, and wound contraction [6]. The antioxidant molecules of ABS detected in our study may be placed into those complicated interactions. However, the exact ABS mechanism-of-action in the wound healing process should be investigated in future experimental studies.

Apigenin has been detected in the molecular library of ABS in this present study. Apigenin has inhibitory effects against the snake venom metalloproteases, the main component accountable for the hemorrhage and tissue degradation at the bitten site [59]. Therefore, the already established antihemorrhagic efficacy of ABS and its apigenin content shall be searched in future toxicological experiments. Likewise, tocopherol and tocotrienol have been detected inside ABS in our study. Tocotrienol is an antioxidant which has been found commercial application as a food additive and health supplement. Tocotrienol $2 \%$ in powdered basal diet in rats had led to the hemorrhage of several organs by week 50 in a previous study [60]. Tocotrienol can induce apoptosis and suppress cellular proliferation [61-64] and has antiangiogenic effects [65]. Therefore, tocotrienol is considered as a potential anticancer agent [66]. Similarly, ABS can induce apoptosis, regulates cellular proliferation [21, 6769], and decreases tumor vascularization [52]. Experimental antineoplastic activities of ABS have been shown in rats and cancer cell lines [20-22]. The interrelationships between ABS, its antioxidant content, and tocotrienol should be investigated in future experimental neoplastic studies.

When addressing the safety of a given product, the moieties found inside shall be assessed to determine if the levels are safe for the exposed patients in order to perform a risk assessment, based on the available data. This is a limitation of our present study. Previously, the clinical phase I double-blinded, randomized, cross-over, placebo-controlled clinical study with a 5 days' washout period between the cross-over periods in healthy volunteers indicated the safety of ABS [15]. Controlled clinical trials [11-18] also have not indicated any safety alert in association with the clinical use of Ankaferd hemostat. However, further clinical trials shall be designed to test clinical responses to Ankaferd hemostat as well as the parallel biological tests focusing on the moieties found inside the hemostatic agent to determine if the levels are safe for the exposed patients.

Clinical studies indicated that topical ABS is a safe and effective haemostatic agent for many different types of internal and external bleedings that are resistant to treatment with conventional antihemorrhagic methods [11-18]. The ability of $A B S$ to induce formation of a protein network regulating the RBC-fibrinogen interactions not only makes it an effective hemostatic agent but also confers anti-infective, antineoplastic, and healing modulator properties. WHO Guidelines [70] for good clinical practice (GCP) for trials on pharmaceutical products (World Health Organization, WHO Technical Report Series, number 850, 1995, Annex 3) clearly indicated that "all research involving human subjects should be conducted in accordance with the ethical principles contained in the current version of the Declaration of Helsinki. Three basic ethical principles should be respected, namely justice, respect for persons, and beneficence (maximizing benefits and minimizing harms and wrongs) or non-malfeasance (doing no harm), as defined by the current revision of the International Ethical Guidelines for Biomedical Research Involving Human Subjects or the laws and regulations of the country in which the research is conducted, whichever represents the greater protection for subjects." Accordingly, Ankaferd hemostat has been searched in this study for the potential toxic agents regarding the assessment of safety. Present in vitro study indicated that no potential toxic substance present in ABS, enabling future in vivo studies. The present toxicological results indicating the safety of $\mathrm{ABS}$ have provided the basis for the upcoming trials. Future clinical and experimental controlled studies are needed to shed further light on the expanding spectrum of ABS effects in clinical hemostasis, wound healing, burn treatment, and anti-infective and antineoplastic approaches. 


\section{Conflict of Interests}

The authors declare that there is no conflict of interests regarding the publication of this paper.

\section{References}

[1] B. Z. Haznedaroglu, Y. Beyazit, S. L. Walker, and I. C. Haznedaroglu, "Pleiotropic cellular, hemostatic, and biological actions of Ankaferd hemostat," Critical Reviews in Oncology/Hematology, vol. 83, no. 1, pp. 21-34, 2012.

[2] D. Ozel-Demiralp, N. Igci, B. Ayhan, Y. Egin, I. C. Haznedaroglu, and N. Akar, "Prohemostatic and antithrombin activities of ankaferd hemostat are linked to fibrinogen gamma chain and prothrombin by functional proteomic analyses," Clinical and Applied Thrombosis/Hemostasis, vol. 18, no. 6, pp. 604-610, 2012.

[3] Y. Beyazit, M. Kurt, M. Kekilli, H. Goker, and I. C. Haznedaroglu, "Evaluation of hemostatic effects of Ankaferd as an alternative medicine," Alternative Medicine Review, vol. 15, no. 4, pp. 329-336, 2010.

[4] C. Akalin, S. Kuru, A. M. Barlas et al., "Beneficial effects of Ankaferd Blood Stopper on dermal wound healing: an experimental study," International Wound Journal, vol. 11, no. 1, pp. 64-68, 2014.

[5] N. Y. Gül Satar, I. T. Cangül, A. Topal, A. Oktay, K. Inan, and M. B. Akgül, "Effects of Ankaferd Blood Stopper (ABS) and topical tripeptide copper complex (TCC) on wound healing in Rats: an experimental study," Kafkas Universitesi Veteriner Fakultesi Dergisi, vol. 20, no. 4, pp. 545-551, 2014.

[6] H. Kaya, M. T. Gokdemir, O. Sogut, T. Demir, and S. Koçarslan, "Effects of folk medicinal plant extract ankaferd blood stopper on burn wound healing," Acta Medica Mediterranea, vol. 29, no. 3, pp. 497-502, 2013.

[7] T. Korkmaz, N. G. Sarikas, A. Kilicgun, E. Serin, and C. Boran, "The mechanism of activity of ankaferd blood stopper in the control of arterial bleeding and in the process of wound healing," HealthMED, vol. 6, no. 11, pp. 3736-3743, 2012.

[8] S. Yüce, C. Çandirli, S. Yenidünya, and B. Muslu, "New hemostatic agent: the effect of ankaferd blood stopper on healing wounds in experimental skin incision model," Turkish Journal of Medical Sciences, vol. 44, no. 2, pp. 288-294, 2014.

[9] D. O. Demiralp, I. C. Haznedaroglu, and N. Akar, "Functional proteomic analysis of Ankaferd (R) Blood Stopper," Turkish Journal of Hematology, vol. 27, no. 2, pp. 70-77, 2010.

[10] E. Yilmaz, S. Gulec, D. Torun, I. C. Haznedaroglu, and N. Akar, "The effects of Ankaferd (R) Blood Stopper on transcription factors in HUVEC and the erythrocyte protein profile," Turkish Journal of Hematology, vol. 28, no. 4, pp. 276-285, 2011.

[11] H. O. Kazancıoğlu, O. Çakir, G. Ak, and B. Zülfikar, "The effectiveness of a new hemostatic agent (Ankaferd blood stopper) for the control of bleeding following tooth extraction in hemophilia: a controlled clinical trial," Turkish Journal of Hematology, vol. 30, no. 1, pp. 19-24, 2013.

[12] A. M. Teker, A. Y. Korkut, O. Gedikli, and V. Kahya, "Prospective, controlled clinical trial of Ankaferd Blood Stopper in children undergoing tonsillectomy," International Journal of Pediatric Otorhinolaryngology, vol. 73 , no. 12, pp. 1742-1745, 2009.

[13] A. M. Teker, A. Y. Korkut, V. Kahya, and O. Gedikli, "Prospective, randomized, controlled clinical trial of Ankaferd Blood
Stopper in patients with acute anterior epistaxis," European Archives of Oto-Rhino-Laryngology, vol. 267, no. 9, pp. 1377-1381, 2010.

[14] M. Z. Amer, S. I. Mourad, A. S. Salem, and E. Abdelfadil, "Correlation between international normalized ratio values and sufficiency of two different local hemostatic measures in anticoagulated patients," European Journal of Dentistry, vol. 8, no. 4, pp. 475-480, 2014.

[15] O. S. Balcik, M. Koroglu, H. Cipil et al., "A placebo-controlled, randomized, double-blinded, cross-over phase-I clinical study indicating the safety of topical ankaferd hemostat in healthy volunteers," UHOD: Uluslararasi Hematoloji-Onkoloji Dergisi, vol. 22, no. 4, pp. 267-274, 2012.

[16] M. Guler, G. Maralcan, S. Kul, I. Baskonus, and M. Yilmaz, "The efficacy of ankaferd blood stopper for the management of bleeding following total thyroidectomy," Journal of Investigative Surgery, vol. 24, no. 5, pp. 205-210, 2011.

[17] M. E. Odabaş, C. Çinar, Ö. Tulunoglu, and B. Işik, "A new Haemostatic agent's effect on the success of calcium hydroxide pulpotomy in primary molars," Pediatric Dentistry, vol. 33, no. 7, pp. 529-534, 2011.

[18] H. Yasar and H. Ozkul, "Haemostatic effect of ankaferd blood stopper (R) seen during adenoidectomy," African Journal of Traditional Complementary and Alternative Medicines, vol. 8, no. 4, pp. 444-446, 2011.

[19] T. Patiroglu, N. G. Sahin, and E. Unal, "Efficacy of Ankaferd Blood Stopper in prophylaxis and treatment of oral mucositis in pediatric malignancies: a pilot study," in Proceedings of the World Federation of HemophiliaWorld Congress (WFH '14), Melbourne, Australia, May 2014.

[20] F. Avcu, M. Guner, M. Misirci et al., "Evaluation of antineoplastic effects of a new hemostatic agent ankaferd blood stopper on myeloma cell line and plasmocytoma development in Balb/c mice: results of the first in vitro and in vivo study," Blood, vol. 124, no. 21, article 5728, 2014.

[21] M. Mumcuoglu, D. F. Akin, U. Ezer, and N. Akar, "Ankaferd Blood Stopper induces apoptosis and regulates PAR1 and EPCR expression in human leukemia cells," Egyptian Journal of Medical Human Genetics, vol. 16, no. 1, pp. 19-27, 2015.

[22] I. Akalin, F. V. Okur, I. C. Haznedaroglu, N. Sayinalp, S. Aksu, and Y. Buyukasik, "Acute in vitro effects of ABS (Ankaferd Hemostat) on the lymphoid neoplastic cells (B-CLL and RAJI tumor cell lines)," Uhod-Uluslararasi Hematoloji-Onkoloji Dergisi, vol. 24, pp. 253-259, 2014.

[23] A. Deveci, A. Y. Çoban, Y. Tanriverdi Çayci et al., "In Vitro effect of ankaferd blood stopper ${ }^{\circledR}$, a plant extract against mycobacterium tuberculosis Isolates," Mikrobiyoloji Bulteni, vol. 47, no. 1, pp. 71-78, 2013.

[24] Y. Beyazit, M. Kekilli, I. C. Haznedaroglu, E. Kayacetin, and M. Basaranoglu, "Ankaferd hemostat in the management of gastrointestinal hemorrhages," World Journal of Gastroenterology, vol. 17, no. 35, pp. 3962-3970, 2011.

[25] M. Kurt, M. Akdogan, I. K. Onal et al., "Endoscopic topical application of Ankaferd Blood Stopper for neoplastic gastrointestinal bleeding: a retrospective analysis," Digestive and Liver Disease, vol. 42, no. 3, pp. 196-199, 2010.

[26] M. Kurt, E. Oztas, S. Kuran, I. K. Onal, M. Kekilli, and I. C. Haznedaroglu, "Tandem oral, rectal, and nasal administrations of Ankaferd Blood Stopper to control profuse bleeding leading to hemodynamic instability," American Journal of Emergency Medicine, vol. 27, no. 5, pp. 631.e1-631.e2, 2009. 
[27] A. Karaman, M. Baskol, S. Gursoy et al., "Endoscopic topical application of ankaferd blood stopper ${ }^{\circledR}$ in gastrointestinal bleeding," Journal of Alternative and Complementary Medicine, vol. 18, no. 1, pp. 65-68, 2012.

[28] N. Akkoç, M. Akçelik, I. C. Haznedaroğlu et al., "In vitro antibacterial activities of ankaferd medicinal plant extract," Turkiye Klinikleri Tip Bilimleri Dergisi, vol. 29, no. 2, pp. 410-415, 2009.

[29] Z. Saribas, B. Sener, I. C. Haznedaroglu, G. Hascelik, S. Kirazli, and H. Goker, "Antimicrobial activity of Ankaferd Blood Stopper ${ }^{\circledR}$ against nosocomial bacterial pathogens," Central European Journal of Medicine, vol. 5, no. 2, pp. 198-202, 2010.

[30] N. T. Fisgin, Y. T. Cayci, A. Y. Coban et al., "Antimicrobial activity of plant extract Ankaferd Blood Stopper ${ }^{\circledR}$, , Fitoterapia, vol. 80, no. 1, pp. 48-50, 2009.

[31] S. Ciftci, F. Keskin, S. K. Ozcan et al., "In vitro antifungal activity of Ankaferd Blood Stopper against Candida albicans," Current Therapeutic Research-Clinical and Experimental, vol. 72, no. 3, pp. 120-126, 2011.

[32] R. Hasgul, S. Uysal, H. Haltas et al., "Protective effects of Ankaferd blood stopper on aspirin-induced oxidative mucosal damage in a rat model of gastric injury," Toxicology and Industrial Health, vol. 30, no. 10, pp. 888-895, 2014.

[33] I. C. Haznedaroglu, "Molecular basis of the pleiotropic effects of ankaferd blood stopper," IUBMB Life, vol. 61, no. 3, article 290, 2009.

[34] K. Molly, M. V. Woestyne, I. DeSmet, and W. Verstraete, "Validation of the simulator of the human intestinal microbial ecosystem (SHIME) reactor using microorganism-associated activities," Microbial Ecology in Health and Disease, vol. 7, no. 4, pp. 191-200, 1994.

[35] M. Xiao, Y. Shao, W. Yan, and Z. Zhang, "Measurement and correlation of solubilities of apigenin and apigenin 7-Orhamnosylglucoside in seven solvents at different temperatures," The Journal of Chemical Thermodynamics, vol. 43, no. 3 , pp. 240-243, 2011.

[36] A. A. Albahrani, V. Rotarou, P. J. Roche, and R. F. Greaves, "Comparison of three commercial calibrators for alphatocopherol using liquid chromatography-tandem mass spectrometry," Clinical Biochemistry, vol. 46, no. 18, pp. 1884-1888, 2013.

[37] M. Gunay and R. Amanvermez, "The effect of Ankaferd on bone fracture healing," Clinical Chemistry and Laboratory Medicine, vol. 49, p. S828, 2011.

[38] B. Z. Haznedaroglu, I. C. Haznedaroglu, S. L. Walker et al., "Ultrastructural and morphological analyses of the in vitro and in vivo hemostatic effects of Ankaferd blood stopper," Clinical and Applied Thrombosis/Hemostasis, vol. 16, no. 4, pp. 446-453, 2010.

[39] C. Akarsu, M. U. Kalayci, E. Yavuz et al., "Comparison of the hemostatic efficiency of Ankaferd Blood Stopper and fibrin glue on a liver laceration model in rats," Turkish Journal of Trauma \& Emergency Surgery, vol. 17, no. 4, pp. 308-312, 2011.

[40] E. Akbal, S. Köklü, G. Karaca et al., "Beneficial effects of ankaferd blood stopper on caustic esophageal injuries," Diseases of the Esophagus, vol. 25, no. 3, pp. 188-194, 2011.

[41] E. Akbal, S. Köklü, G. Karaca et al., "Beneficial effects of Ankaferd Blood Stopper on caustic esophageal injuries: an experimental model," Diseases of the Esophagus, vol. 25, no. 3, pp. 188-194, 2012.

[42] A. Aktaş, N. Er, and P. Korkusuz, "Ankaferd-induced early wound healing of soft tissue in an experimental rat model," Turkiye Klinikleri Tip Bilimleri Dergisi, vol. 31, pp. 185-195, 2012.
[43] A. Alpay, S. Bektas, A. Alpay, S. C. Ugurbas, C. Evren, and S. H. Ugurbas, "Effects of a new hemostatic agent Ankaferd Blood Stopper ${ }^{\circledR}$ on the intraocular tissues in rat model," Cutaneous and Ocular Toxicology, vol. 31, no. 2, pp. 128-131, 2012.

[44] A. Alpay, S. C. Ugurbas, C. Evren, S. Bektas, S. Çaliskan, and S. H. Ugurbas, "Use of a novel haemostatic agent: ankaferd blood stopper in conjunctival incisions," Clinical and Experimental Ophthalmology, vol. 39, no. 8, pp. 793-798, 2011.

[45] S. Arslan, I. C. Haznedaroglu, B. Öz, and H. Goker, "Endobronchial application of Ankaferd blood stopper to control profuse lung bleeding leading to hypoxemia and hemodynamic instability," Respiratory Medicine CME, vol. 2, no. 3, pp. 144-146, 2009.

[46] Y. Beyazit, S. Köklü, E. Akbal, M. Kurt, M. Kekilli, and I. C. Haznedaroglu, "Successful treatment of endoscopic sphincterotomyinduced early hemorrhage with application of Ankaferd Blood Stopper," Gastrointestinal Endoscopy, vol. 72, no. 6, pp. 1325-1326, 2010.

[47] E. Eren, M. S. Başoğlu, E. Kulduk, F. Şimsek, and S. Inan, "Mucosal trauma induced apoptosis in guinea pig middle ear: comparision of hemostatic agents," International Journal of Pediatric Otorhinolaryngology, vol. 78, no. 12, pp. 2222-2228, 2014.

[48] Y. Beyazit, E. Huri, T. Purnak, M. O. Guler, and I. C. Haznedaroglu, "Next generation nanomedicine in the genesis of 'Ankaferd blood stopper nanohemostat': a novel chimeric topical hemostatic agent for clinical hemorrhages," Clinical and Applied Thrombosis-Hemostasis, vol. 20, no. 4, pp. 456-457, 2014.

[49] E. Huri, Y. Beyazit, R. Mammadov et al., "Generation of chimeric 'ABS nanohemostat' complex and comparing its histomorphological In vivo effects to the traditional Ankaferd hemostat in controlled experimental partial nephrectomy model," International Journal of Biomaterials, vol. 2013, Article ID 949460, 10 pages, 2013.

[50] V. Şen, Ü. Uluca, A. Ece et al., "Role of Ankaferd on bacterial translocation and inflammatory response in an experimental rat model of intestinal obstruction," International Journal of Clinical and Experimental Medicine, vol. 7, no. 9, pp. 2677-2686, 2014.

[51] A. Taş, S. Köklü, Y. Beyazit et al., "Percutaneous ankaferd injection to in vivo liver tissue in comparison to ethanol in an experimental rat model," Clinics and Research in Hepatology and Gastroenterology, vol. 35, no. 8-9, pp. 549-553, 2011.

[52] N. Turhan, M. Kurt, A. Shorbagi, M. Akdogan, and I. C. Haznedaroglu, "Topical ankaferd blood stopper administration to bleeding gastrointestinal carcinomas decreases tumor vascularization," The American Journal of Gastroenterology, vol. 104, no. 11, pp. 2874-2877, 2009.

[53] E. Akbal, S. Köklü, H. M. Astarci et al., “Oral high-dose ankaferd administration effects on gastrointestinal system," International Journal of Medical Sciences, vol. 10, no. 4, pp. 451-456, 2013.

[54] A. Aktas, N. Er, and M. A. Onur, "Effects of ankaferd blood stopper $^{\circledR}$ on vascular response in rat carotid artery," UhodUluslararasi Hematoloji-Onkoloji Dergisi, vol. 20, no. 3, pp. 156$162,2010$.

[55] A. Durhan, S. Tuncal, K. Kismet et al., "Evaluation of intraabdominal adhesion generating potentials of ankaferd and calcium alginate used as hemostatic agents," Bratislava Medical Journal, vol. 115, no. 9, pp. 544-549, 2014. 
[56] K. Karaman, B. Celep, E. B. Bostanci et al., "Effects of ankaferd blood stopper on pancreatic fluid: an in vitro study," $A N Z$ Journal of Surgery, vol. 80, no. 12, pp. 946-947, 2010.

[57] E. Koçak, E. Akbal, A. Tas et al., "Anti-inflammatory efficiency of Ankaferd blood stopper in experimental distal colitis model," Saudi Journal of Gastroenterology, vol. 19, no. 3, pp. 126-130, 2013.

[58] E. Yavuz, M. U. Kalayci, S. Kesici, U. Kesici, S. Ozkara, and O. Yalcin, "Efficacy of ankaferd blood stopper in bleeding control in experimental partial splenectomy model," Kafkas Universitesi Veteriner Fakultesi Dergisi, vol. 18, no. 5, pp. 753-758, 2012.

[59] V. Srinivasa, M. S. Sundaram, S. Anusha et al., "Novel apigenin based small molecule that targets snake venom metalloproteases," PLoS ONE, vol. 9, no. 9, Article ID e106364, 2014.

[60] M. Tasaki, T. Umemura, T. Inoue et al., "Induction of characteristic hepatocyte proliferative lesion with dietary exposure of Wistar Hannover rats to tocotrienol for 1 year," Toxicology, vol. 250, no. 2-3, pp. 143-150, 2008.

[61] A. Inoue, K. Takitani, M. Koh, C. Kawakami, T. Kuno, and H. Tamai, "Induction of apoptosis by $\gamma$-tocotrienol in human cancer cell lines and leukemic blasts from patients: dependency on bid, cytochrome c, and caspase pathway," Nutrition and Cancer, vol. 63, no. 5, pp. 763-770, 2011.

[62] S. W. Lim, H. S. Loh, K. N. Ting, T. D. Bradshaw, and N. A. Zeenathul, "Cytotoxicity and apoptotic activities of alpha-, gamma- and delta-tocotrienol isomers on human cancer cells," BMC Complementary and Alternative Medicine, vol. 14, article 469, 2014.

[63] M. Sakai, M. Okabe, H. Tachibana, and K. Yamada, "Apoptosis induction by $\gamma$-tocotrienol in human hepatoma Hep3B cells," Journal of Nutritional Biochemistry, vol. 17, no. 10, pp. 672-676, 2006.

[64] S. Wada, Y. Satomi, M. Murakoshi, N. Noguchi, T. Yoshikawa, and H. Nishino, "Tumor suppressive effects of tocotrienol in vivo and in vitro," Cancer Letters, vol. 229, no. 2, pp. 181-191, 2005.

[65] T. Miyazawa, A. Shibata, K. Nakagawa, and T. Tsuzuki, "Antiangiogenic function of tocotrienol," Asia Pacific Journal of Clinical Nutrition, vol. 17, supplement 1, pp. 253-256, 2008.

[66] M. T. Ling, S. U. Luk, F. Al-Ejeh, and K. K. Khanna, “Tocotrienol as a potential anticancer agent," Carcinogenesis, vol. 33, no. 2, pp. 233-239, 2012.

[67] E. Huri, T. Akgul, M. Astarci, H. Ustun, and C. Germiyanoglu, "The effect of a novel hemostatic agent, Ankaferd bloodstopper (R) (Abs), on renal tubular apoptosis in rat partial nephrectomy model," Journal of Endourology, vol. 23, article A2, 2009.

[68] E. Huri, I. C. Haznedaroglu, T. Akgul, M. Astarci, H. Ustun, and C. Germiyanoulu, "Biphasic effects of ankaferd blood stopper on renal tubular apoptosis in the rat partial nephrectomy model representing distinct levels of hemorrhage," Saudi Medical Journal, vol. 31, no. 8, pp. 864-868, 2010.

[69] A. Mihmanli, Z. Ulker, L. Alpsoy, and S. Ezirganli, "Evaluation of cytotoxicity of a new hemostatic agent Ankaferd Blood Stopper ${ }^{\circledR}$ using different assays," Human \& Experimental Toxicology, vol. 31, no. 8, pp. 780-787, 2012.

[70] World Health Organization, "Guidelines for good clinical practice (GCP) for trials on pharmaceutical products," WHO Technical Report Series 850, Annex 3, World Health Organization, 1995. 


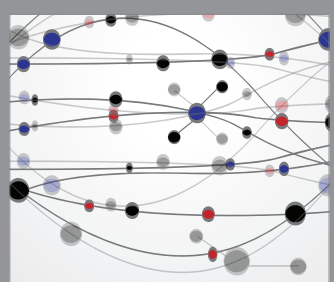

The Scientific World Journal
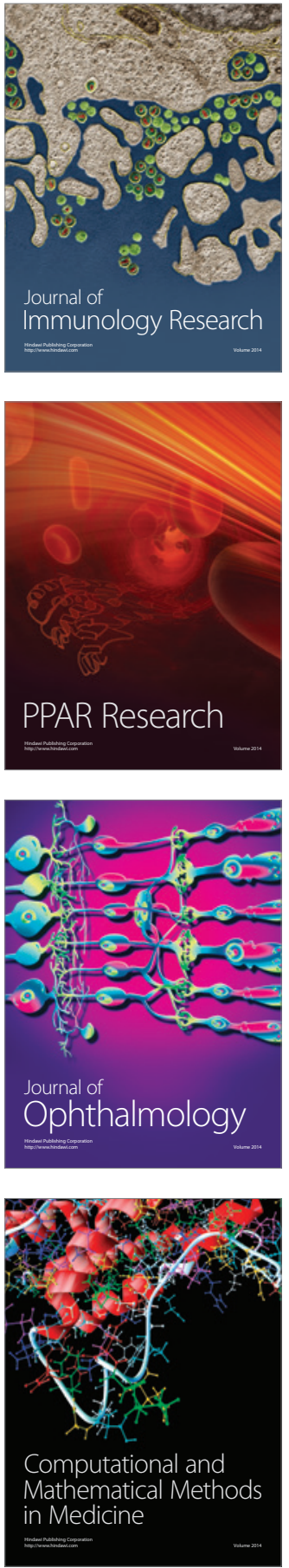

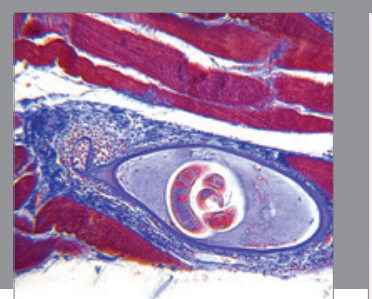

Gastroenterology Research and Practice

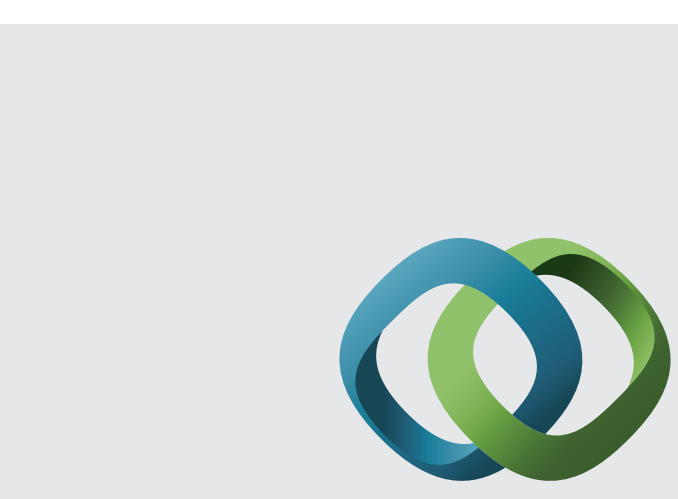

\section{Hindawi}

Submit your manuscripts at

http://www.hindawi.com
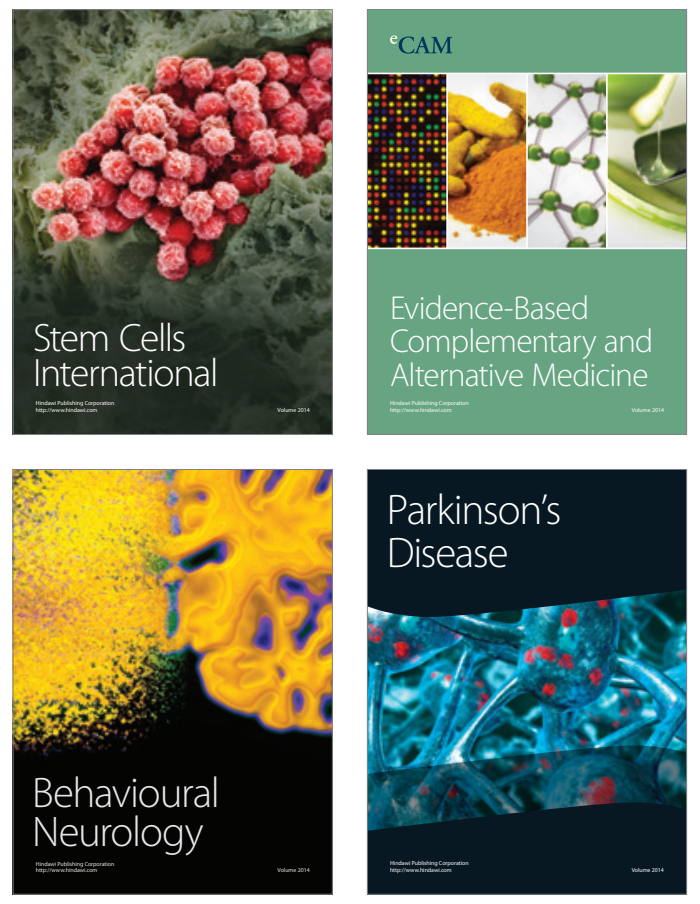
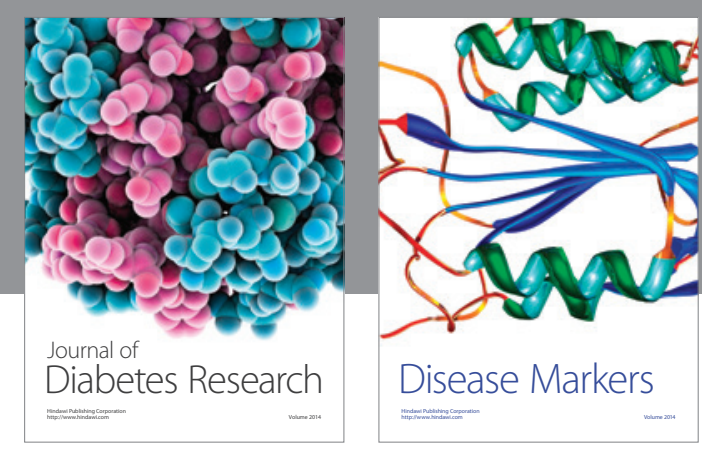

Disease Markers
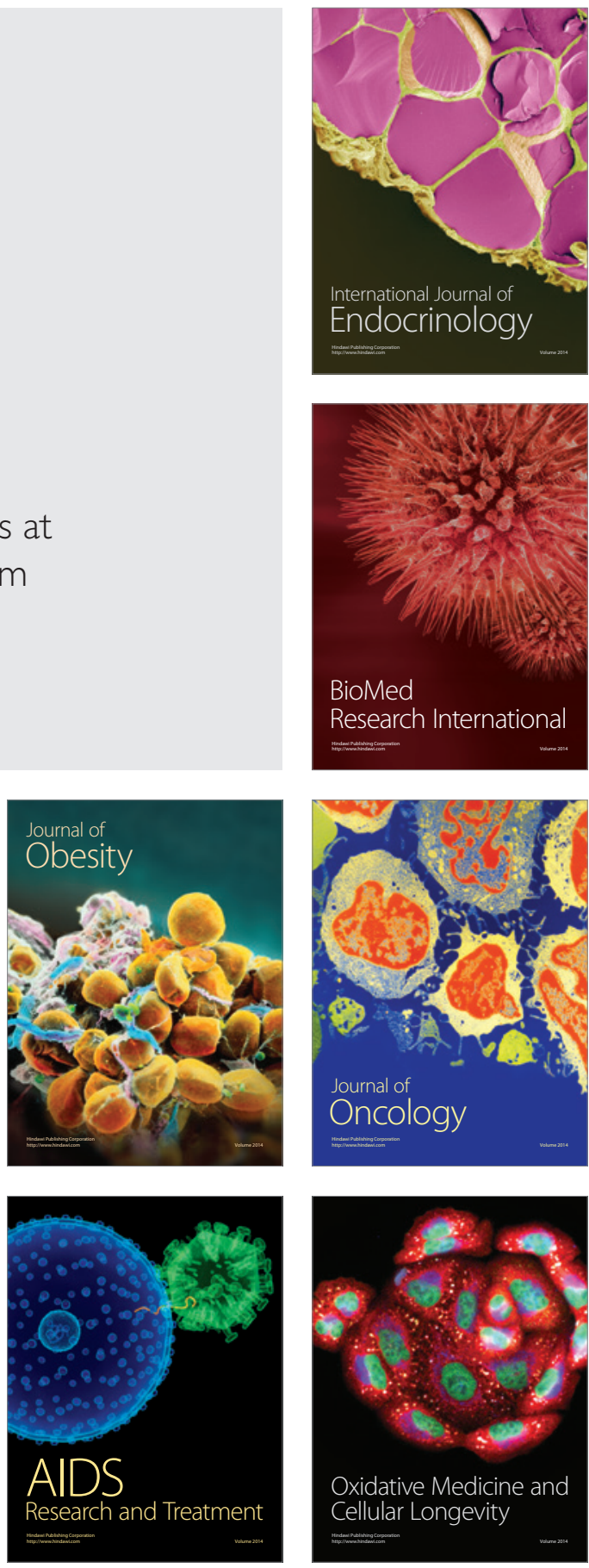